\title{
Article
}

\section{Visiting the "enemy": visitation in politically unstable destinations}

Farmaki, Anna, Antoniou, Katerina and Christou, Prokopis

Available at http://clok.uclan.ac.uk/28736/

Farmaki, Anna, Antoniou, Katerina and Christou, Prokopis (2019) Visiting the "enemy": visitation in politically unstable destinations. Tourism Review, 74

(3). pp. 293-309. ISSN 1660-5373

It is advisable to refer to the publisher's version if you intend to cite from the work. http://dx.doi.org/10.1108/tr-11-2018-0159

For more information about UCLan's research in this area go to

http://www.uclan.ac.uk/researchgroups/ and search for < name of research Group>.

For information about Research generally at UCLan please go to http://www.uclan.ac.uk/research/

All outputs in CLoK are protected by Intellectual Property Rights law, including Copyright law. Copyright, IPR and Moral Rights for the works on this site are retained by the individual authors and/or other copyright owners. Terms and conditions for use of this material are defined in the policies page.

\section{CLoK}

Central Lancashire online Knowledge www.clok.uclan.ac.uk

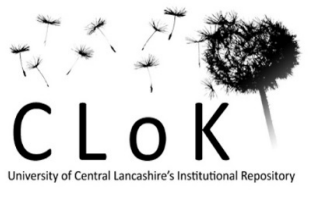




\section{eemeraldinsight}

\section{Tourism Review}

Visiting the "enemy": visitation in politically unstable destinations

Anna Farmaki, Katerina Antoniou, Prokopis Christou,

\section{Article information:}

To cite this document:

Anna Farmaki, Katerina Antoniou, Prokopis Christou, (2019) "Visiting the "enemy": visitation in politically unstable destinations", Tourism Review, https://doi.org/10.1108/TR-11-2018-0159

Permanent link to this document:

https://doi.org/10.1108/TR-11-2018-0159

Downloaded on: 30 May 2019, At: 02:57 (PT)

References: this document contains references to 50 other documents.

To copy this document: permissions@emeraldinsight.com

Access to this document was granted through an Emerald subscription provided by Token:Eprints:IMRWGWRFJ TJ 9MTII9YPZ:

\section{For Authors}

If you would like to write for this, or any other Emerald publication, then please use our Emerald for Authors service information about how to choose which publication to write for and submission guidelines are available for all. Please visit www. emeraldinsight. com/ authors for more information.

\section{About Emerald www.emeraldinsight.com}

Emerald is a global publisher linking research and practice to the benefit of society. The company manages a portfolio of more than 290 journals and over 2,350 books and book series volumes, as well as providing an extensive range of online products and additional customer resources and services.

Emerald is both COUNTER 4 and TRANSFER compliant. The organization is a partner of the Committee on Publication Ethics (COPE) and also works with Portico and the LOCKSS initiative for digital archive preservation.

*Related content and download information correct at time of download. 


\title{
Visiting the "enemy": visitation in politically unstable destinations
}

\author{
Anna Farmaki, Katerina Antoniou and Prokopis Christou
}

\begin{abstract}
Purpose - This study aims to examine the factors shaping the intentions of people to visit a hostile outgroup. Design/methodology/approach - An exploratory, qualitative research approach was followed. Specifically, 77 semi-structured interviews with citizens of the divided island of Cyprus were conducted.

Findings - This study identifies several categories of visitors and non-visitors, depicted along a continuum, and concludes that there is a multiplicity of factors in the socio-political environment which influence the travel intentions of people.

Originality/value - This study not only imparts insights into the way travel decision-making evolves in politically unstable situations but also serves as a stepping stone towards understanding the conditions under which reconciliation between hostile nations may be encouraged by travel.
\end{abstract}

Keywords Cyprus, Travel intentions, Political instability, Reconciliation

Paper type Research paper

\section{Introduction}

The pursuit for refined marketing and improved destination management led to a proliferation of studies investigating travel-related aspects, such as tourist motives and experiences, within different settings and applied across various tourist segments. Within this context, an important body of literature investigating the effects of political instability on travel behaviour can be found. In fact, the recent increase in political instability and conflict around the world has reignited academic interest on the impact of uncertainty and tension on people's perceptions, attitudes and travel decision-making (Farmaki et al, 2019). An overview of extant literature reveals two main streams of research. First, there are studies investigating the effects of political crises on the tourism activity (Alvarez and Campo, 2014; Causevic and Lynch, 2013), which conclude that political instability has a negative influence on tourist arrivals and destination image. Nevertheless, the majority of past studies focussed investigation on tourists' potential reactions immediately after the crisis (Hajibaba et al., 2015). Considering that a political crisis is usually short-lived with tourist demand recovering soon after the crisis is overcome (Coshall, 2003), there is a lack of research "in the context of an ongoing crisis situation" (Alvarez and Campo, 2014: p. 71).

Indeed, the damage inflicted by negative events caused by political conflict transcends beyond economic considerations as political crises have been found to impact intercultural dialogue, with animosity being identified as a key influencer on travel behaviour (Podoshen and Hunt, 2011; Stepchenkova et al, 2018). In this respect, a second stream of research emerged, as an increasing number of scholars began to view tourism as a potential contributor to peace between countries that are currently or previously in conflict (Chen, 2010; Durko and Petrick, 2015). Nonetheless, these studies yield inconclusive findings, supporting the argument that prolonged political instability leads to a more permanent effect on people's perceptions and attitudes (Sönmez and Graefe, 1998). Unsurprisingly,
Anna Farmaki is based at the Department of Hotel and Tourism Management, Cyprus University of Tehcnology, Limassol, Cyprus. Katerina Antoniou is based at the School of Business and Management, University of Central Lancashire Cyprus Campus, Pyla, Cyprus. Prokopis Christou is based at the Department of Hotel and Tourism Management, Cyprus University of Technology, Lemesos, Cyprus.

Received 7 November 2018 Revised 6 January 2019 Accepted 19 February 2019 
Chen et al (2016: p. 26) questioned "whether negative views toward a hostile nation could be easily changed after a few travel experiences between the nations". Whilst there are several studies that investigated travel-related aspects of people from hostile countries (Anastasopoulos, 1992; Chen, 2010; Chen et al., 2016; Cho, 2007; Durko and Petrick, 2015), the majority relied on quantitative research methods which to a great extent fail to capture the complexity and dynamic nature underpinning people's travel intentions in politically unstable environments.

This study adopts an exploratory, qualitative approach to examine the intentions of people to visit a hostile outgroup. Drawing from the divided Island of Cyprus, we consider the factors shaping travel related decision-making in situations of prolonged political instability and thus contribute to general literature on travel in politically unstable and hostile contexts. Specifically, an examination of the contextual factors influencing travel intentions between hostile nations allows for greater understanding of the vulnerability of tourism to sociopolitical conditions. Additionally, insights are drawn that enhance knowledge on the conditions under which travel might contribute to the reconciliation efforts between hostile countries and, as such, to the achievement of peace. In particular, by considering both the reasons motivating and inhibiting people to visit a hostile outgroup, greater understanding is gained on the complexity characterising travel decision-making in politically unstable contexts. Considering the current context of instability in which global tourism operates and the intensification of prejudicial attitudes influencing the tourism activity, we believe this paper represents a timely addition to extant literature.

\section{Literature review \\ Political instability and tourism}

The literature looking at the influence of political instability on tourism is expansive, with studies taking place in various settings and adopting different research perspectives. Two main conclusions may be drawn from studies examining the interface between political tension and tourism. First, political crises lead to a direct, negative impact on tourism (Alvarez and Campo, 2014; Neumayer, 2004). Specifically, extant literature suggests that political instability, emanating from several events such as terrorism, war and/or other violent incidents, has a direct negative impact on tourist arrivals and country image (Arana and Leon, 2008; Causevic and Lynch, 2013; Clements and Georgiou, 1998; Drakos and Kutan, 2003; Saha and Yap, 2014). Much of the discourse on post-crisis travel utilises risk theory (Chew and Jahari, 2014; Hajibaba et al., 2015), identifying safety and security issues as important predictors of travel avoidance. This is not surprising as tourists generally select low-risk destinations (Sönmez and Graefe, 1998) whereas in the case of a crisis, perceived travel risk increases thereby inhibiting a potential visit. Despite the important insights gained from these studies, they only partly explain why people will not visit a destination. On the one hand, they ignore the fact that tourists perceive risk differently in different situations and towards different destinations (Chew and Jahari, 2014). On the other hand, studies focussing on the impact of crises on travel investigate tourists' potential reactions immediately after a crisis (Hajibaba et al., 2015). Nonetheless, with appropriate management mechanisms destinations facing a crisis can achieve a fast recovery. However, this may not be the case in destinations that are subjected to continuous political turmoil, as they experience a more permanent effect on perceptions and attitudes (Sönmez and Graefe, 1998).

This brings us to the second conclusion emanating from the political instability and tourism literature. It has been argued that the damage inflicted by political conflicts transcends beyond economic considerations, as political crises impact intercultural dialogue, with animosity being identified as a key influencer on travel intentions (Podoshen and Hunt, 2011; Stepchenkova et al., 2018). As such, there is an important a stream of research closely linked to political instability influences, which views tourism not as a victim of political 
tension but rather as an agent of peace. Emanating from the inspiring work of D'Amore (1988), who invited researchers to consider the role of tourism in establishing peace, an important pool of studies exists advocating that travel may reduce tensions and harmonise relations between societies that have undergone prolonged conflict, by improving visitors' negative perceptions and attitudes towards the visited community (Chen, 2010; Durko and Petrick, 2015; Guo et al., 2006; Higgins-Desbiolles, 2003). Nonetheless, the studies in this research domain yield inconclusive findings revealing that the rhetoric on the contributory role of tourism to peace remains largely unsubstantiated. For example, Chen's (2010) study on travel between China and Taiwan and Kim et al. (2007) investigation of visits from South Koreans to North Korea reveal some positive effects on perceptions and attitudes. In explaining this positive effect, Chen et al. (2016: p. 26) suggested that "divided nations might not be analogous to other cases of international conflict in that the cultural distance between divided nations is not typically large" as their people anticipate future reunification (Kim and Prideaux, 2003). However, other studies focussing on the context of divided nations highlight the rigidity of people's perceptions and attitudes, as a result of prolonged instability (Chen et al., 2016). For instance, Kim and Prideaux's (2006) study on Southern Koreans' perceptions of their counterparts in the northern peninsula reported minimal interest to visit Mt Gumgang due to political tensions. Likewise, several scholars questioned the positive effect of travel on the perceptions and attitudes of people of divided nations (Cho, 2007; Chen et al., 2016; Guo et al., 2006), highlighting the fluid political environment, mistrust and a lack of cooperation between hostile nations as enhancing negative stereotyping, prejudicial attitudes and animosity among people.

Indeed, even though the damaging effects of a political crisis are usually short-lived, with tourist demand recovering soon after the crisis is overcome (Coshall, 2003), in countries experiencing ongoing political tensions a rigidity of negative perceptions and attitudes exists between opposing groups. As Anastasopoulos (1992) argued, travel does not necessarily improve perceptions between "traditional enemies". In fact, pertinent research identified political tensions and economic relations between hostile countries as influencers on people's perceptions and attitudes (Alvarez and Campo, 2014; Chen et al., 2016; Cho, 2007; Guo et al., 2006), often inhibiting travel intentions (Kim and Prideaux, 2006). Undoubtedly, political instability and conflict between hostile nations is deeply entrenched in the social fabric of their societies that have undergone prolonged political turmoil, shaping people's perceptions and attitudes towards the hostile outgroup and, by extent, their travel intentions. Unsurprisingly, Pratt and Liu's (2016) empirical examination of the tourism and peace relationship in 111 countries confirms Litvin's (1998) argument that tourism is a beneficiary of peace rather than a cause for peace.

Despite the informative insights gained by scholarly work on the political instability and tourism nexus, an overview of the literature reveals certain shortcomings. First, the majority of past studies focussed on "pre-visit and post-visit questionnaires, which did not explore the nature of perceptions of opposing groups" (Farmaki, 2017: p. 537). For instance, minimal academic attention has been paid to the potential unwillingness of people to visit a hostile outgroup. Although Farmaki et al. (2019) examined potential travel demotivating factors between hostile groups, the study was of a quantitative nature. Indeed, in the political instability and tourism literature there is a dominance of quantitative studies investigating primarily micro-level aspects such as the effect of stereotyping on destination image within politically unstable countries (Chen et al., 2016) and/or the influence of country image on intentions to travel to a hostile outgroup (Alvarez and Campo, 2014). However, reliance on conventional survey methods fails to capture the complexity and dynamic nature underpinning people's travel intentions. Second, much of the focus of previous research has been on student groups engaging in an educational, collaborative project (Tomljenovic, 2010). Student participants enjoy equal status with the intergroup contact occurring within a controlled institutionalised environment. In addition, students' status denotes a homogeneity in terms of age and educational level which may not be 
representative of the general population (Alvarez and Campo, 2014). Thus, the degree to which past study findings are reflective of the views of ordinary citizens is questionable.

This study adopts an exploratory, qualitative approach to examine the intentions of people to visit a hostile outgroup. In so doing, we consider the factors shaping travel related decision-making in situations of political instability in an attempt to reflect the intricate sociopolitical environment of destinations experiencing prolonged political turmoil. Specifically, this study seeks to answer the following questions. Why people visit (or not) a hostile outgroup? What are the contextual factors influencing people's intentions to (re)visit a hostile outgroup? To this end, we focus on the divided Island of Cyprus, which is well known for the protracted conflict between its main communities, the Greek Cypriots and Turkish Cypriots.

\section{Cyprus: small island, big conflict}

The Island of Cyprus has been divided since 1974, when Turkish forces occupied approximately 37 per cent of the Island's northern part (Fisher, 2001). The Turkish offence on Cyprus was the aftermath of ongoing tensions between the Island's two main communities, the Greek Cypriots and the Turkish Cypriots, and led to the geographical partition of the two communities, with around 185000 Greek Cypriots being internally displaced to the south of the Island and 45000 Turkish Cypriots respectively relocating in the north (Webster and Timothy, 2006). As a result, the two communities developed separate institutional and governance structures: the Republic of Cyprus (an internationally recognised state and member of the European Union) in the south and the Turkish Cypriot administration in the north which remains a non-recognised de facto state, economically and politically dependent on Turkey. The UN Security Council states that the declaration of the self-proclaimed "Turkish Republic of Northern Cyprus" is legally invalid (Akis et al., 1996) whereas northern Cyprus is considered by the international community as part of the Republic of Cyprus, illegally occupied by Turkey[1]. Likewise, Turkey does not recognise the Republic of Cyprus as legitimate. After living in complete isolation, crossing to the "other" side by each respective community was made possible only in 2003. Within a year and a half, more than 4 million crossings had been registered by Greek and Turkish Cypriots whereas by 2016, more than 15 million crossing were registered for Turkish Cypriots contrary to approximately 9 million crossings by Greek Cypriots (European Commission, 2017). Likewise, approximately 1.1 million tourists crossed in both directions (Diaz-Sauceda et al., 2015). Interestingly, while the Turkish Cypriot community is numerically smaller representing approximately a quarter of the Greek Cypriot community - the number of crossings registered for Turkish Cypriots is noticeably higher.

A selective number of studies investigating the reasons encouraging and/or discouraging crossing to the "other" side exists. Many Greek and Turkish Cypriots crossed initially to visit ancestral land whilst others crossed simply out of curiosity (Dikomitis, 2004; Webster and Timothy, 2006). Shopping, leisure and employment were also found to encourage frequent visitation by Turkish Cypriots while many Greek Cypriots cross for gambling or for visiting sacred places (Farmaki et al., 2019; Webster and Timothy, 2006). Nonetheless, in explaining the lower number of crossings by Greek Cypriots, Bryant (2010) suggested that the initial euphoria of the first crossings subsided when the experience of returning as a kind of domestic tourist led to decisions against a future visit. In fact, a large proportion of the Greek Cypriot community has never visited the northern part of Cyprus. As Scott (2012) suggested, the requirement to show identification to Turkish Cypriot guards upon crossing is a deterring factor for many Greek Cypriots as it is a reminder of the power politics at play. Resistance to cross was found to emanate from a concern that doing so will grant political legitimacy to the "other" side, with Webster and Timothy (2006) and more recently Farmaki et al (2019) arguing that many Greek Cypriots were bound by an ethical imperative not to spend money in the north even in the case of a visit. 
Despite multiple UN-sponsored attempts to reach a viable settlement, little progress towards reunification was made. In 2015, a momentum was reached when negotiation talks intensified with the political leaders of the two communities visiting each side and undertaken join activities. Additionally, several confidence building measures such as the abolishment of the visa requirement by Greek Cypriot visitors were agreed upon. More rounds of negotiation talks followed in 2016 and 2017 to no avail, with the Turkish Cypriots blaming Greek Cypriots for making maximalist demands and Greek Cypriots highlighting Turkey's interference in internal affairs and gas and oil explorations in the Eastern Mediterranean as a negative influencer.

\section{Methodology}

An exploratory qualitative research approach was adopted to collect and analyse the data. A qualitative approach to research was deemed more appropriate, allowing the in-depth exploration of travel decision-making within contexts of political instability and conflict and, specifically, of the factors shaping travel intentions. Consequently, greater insights may be gained not only on the influence of political instability on travel decision-making but also on the conditions under which tourism might contribute the reconciliation of "traditional enemies".

The study centres investigation on the intentions of Greek Cypriots to visit the northern part of the Island. Although it would have been desirable to compare and contrast the view of both communities, for practicality and accessibility issues this study focuses on the views of Greek Cypriots only. Specifically, Greek Cypriots residing in the southern part of the Island were purposively selected. In qualitative sampling, neither statistical representation nor scale are key considerations (Holloway and Wheeler, 2010). Precision and rigour of the qualitative research sample is defined by its ability to represent salient characteristics (Ritchie et al., 2014). The rationale of purposive sampling rests on the fact that the researchers, based on their a-priori theoretical understanding of the topic, assume that certain individuals may have important perspectives on the phenomenon in question (Robinson, 2014). Thus, sample selection considered the backgrounds, age and gender of the informants to ensure that enough diversity is included (Ritchie et al., 2014) within the sample. Table I shows the profile of informants.

Specifically, semi-structured interviews were conducted by an experienced member of the research team on a one-to-one basis and face-to-face. Informants of various age groups, both genders and different socio-economic backgrounds were approached by the principal investigator and asked to participate in the study, after the purpose of the study was explained to them. Participants were assured of their anonymity via the use of pseudonyms. The interviews were performed in the comfort of the participants' homes and/or preferred meeting point (e.g. cafeteria). The interviews, which took place from June to November 2017, lasted approximately 45 to 60 min each with the questions being framed according to the research aim. Specifically, each interview proceeded from a number of "grand tour" questions (McCracken, 1988) seeking to establish the visitation profile of the informants (e.g. visit frequency) before moving into the topic of visitation motives, potential factors inhibiting visitation and visitation experience amongst others. For example, the participants were asked why they have visited or continue to visit northern Cyprus and if so how many times they cross to the "other side". Correspondingly, they were asked to explain the reasons they had not visited or will not visit northern Cyprus. In this respect, informants were asked to elaborate on their visit experience, whether positive or negative. Each interviewee was further probed if necessary and notes were taken before, during and after the interviews to capture verbal and non-verbal aspects of the interviews. Data saturation was reached after 77 interviews.

All interviews were performed in Greek and transcribed, following translation from a professional, into English. The transcripts were checked for accuracy and were analysed 
Table I Profile of informants

\begin{tabular}{|c|c|c|c|}
\hline Pseudonym & Age & Intention to visit & Past Visit \\
\hline Aggela & 29 & Positive & Yes \\
\hline Akis & 32 & Positive & Yes \\
\hline Alexis & 30 & Negative & Yes \\
\hline Andreas & 44 & Positive & Yes \\
\hline Andriani & 52 & Negative & No \\
\hline Anna & 28 & Positive & Yes \\
\hline Anna & 36 & Positive & Yes \\
\hline Annita & 32 & Negative & No \\
\hline Anthi & 77 & Positive & Yes \\
\hline Antonia & 42 & Positive & Yes \\
\hline Antreas & 19 & Positive & Yes \\
\hline Antros & 55 & Positive & Yes \\
\hline Aspasia & 74 & Positive & Yes \\
\hline Chara & 21 & Negative & Yes \\
\hline Charalambos & 44 & Negative & Yes \\
\hline Charis & 29 & Negative & Yes \\
\hline Christakis & 50 & Positive & No \\
\hline Christina & 31 & Positive & No \\
\hline Costas & 30 & Positive & No \\
\hline Demetra & 32 & Negative & Yes \\
\hline Despo & 41 & Positive & Yes \\
\hline Elena & 30 & Positive & Yes \\
\hline Elena & 29 & Negative & Yes \\
\hline Elena & 20 & Negative & No \\
\hline Eleni & 28 & Positive & Yes \\
\hline Eleni & 50 & Negative & Yes \\
\hline Elenitsa & 87 & Positive & Yes \\
\hline Ellie & 56 & Negative & No \\
\hline Evagelia & 30 & Positive & Yes \\
\hline Evi & 17 & Negative & Yes \\
\hline Georgia & 27 & Negative & Yes \\
\hline Georgia & 28 & Negative & Yes \\
\hline Gianoula & 68 & Positive & Yes \\
\hline Giorgos & 19 & Positive & Yes \\
\hline Ioanna & 36 & Positive & No \\
\hline Irene & 29 & Negative & No \\
\hline John & 30 & Positive & Yes \\
\hline Joseph & 61 & Positive & Yes \\
\hline Kalia & 28 & Positive & No \\
\hline Katerina & 40 & Negative & Yes \\
\hline Katerina & 36 & Negative & Yes \\
\hline Konstantina & 30 & Negative & Yes \\
\hline Konstantinos & 36 & Negative & No \\
\hline Kostas & 32 & Negative & No \\
\hline Koulla & 28 & Positive & No \\
\hline Kyriakos & 64 & Positive & Yes \\
\hline Maria & 37 & Positive & No \\
\hline Maria & 29 & Positive & Yes \\
\hline Maria & 27 & Positive & Yes \\
\hline Marinos & 68 & Negative & Yes \\
\hline Marios & 27 & Negative & Yes \\
\hline Maroulla & 87 & Positive & Yes \\
\hline Mary & 27 & Negative & Yes \\
\hline Michalis & 22 & Negative & No \\
\hline Natasa & 33 & Negative & Yes \\
\hline Neofytos & 60 & Negative & No \\
\hline Nicos & 24 & Positive & Yes \\
\hline
\end{tabular}

(continued) 


\begin{tabular}{llll} 
Table I & & & \\
\hline Pseudonym & Age & Intention to visit & Past Visit \\
\hline Niki & 31 & Positive & Yes \\
Niki & 51 & Negative & Yes \\
Nikolas & 34 & Positive & Yes \\
Nitsa & 58 & Negative & Yes \\
Pambos & 67 & Positive & Yes \\
Panagiotis & 77 & Positive & Yes \\
Panayiota & 32 & Positive & Yes \\
Panikkos & Negative & No \\
Panos & 65 & Negative & No \\
Pavlos & 40 & Negative & No \\
Petros & 32 & Negative & Yes \\
Savvas & 33 & Positive & Yes \\
Sophie & 29 & Negative & No \\
Sotos & 47 & Negative & Yes \\
Stelios & 32 & Negative & Yes \\
Stephanie & 56 & Positive & Yes \\
Theodosis & 36 & Negative & Yes \\
Xenia & 65 & Negative & No \\
Yiannis & 45 & Negative & No \\
Yiota & 33 & Positive & Yes \\
& 27 & &
\end{tabular}

using thematic content analysis to illuminate underlying themes in the discussion. Specifically, the analytical process involved the identification, analysis and reporting of patterns within the data set. Data analysis was conducted by all the authors whereas to ensure the integrity of analysis each researcher undertook an initial round of open coding independently to triangulate the initial findings. Investigator triangulation is effective in balancing the subjective interpretations of researchers (Flick, 2000) as a collective comparison of coding schemes was enabled, thereby expanding and clarifying thematic categories. First, the transcripts and notes from the interviews were read several times to familiarise with the data. Then, emergent codes were drawn from the text in an attempt to identify the meaning within a text without any preconceptions. Following several rounds of coding, topics emerging from the data were grouped into interrelated themes. Specifically, blocks of verbatim text were copied, re-organised and cross-referenced to allow the identification of thematic categories. Sub-categories also emerged, which were combined with pre-identified themes to allow for deeper elaboration on key issues that encourage evidence-based understanding (Hennink et al., 2010). Categories of data were related to sub-categories not only to allow for the explanation of the phenomenon under study but also to allow for the differentiation between the narrative accounts provided by the informants. In this regard, themes were reviewed rigorously until a thematic map emerged whereby data under each theme was refined.

\section{Findings and discussion}

In opening the discussion, it is important to note that the majority of informants had, at some point, visited the northern part of the Island. Nonetheless, there were informants who are yet to cross to the "other" side. While at the outset it appeared that informants' visitation pattern was characterised by this dichotomy, as the analysis moved on we identified interplay of factors shaping the decision to (re)visit the "other" side. Reflecting the complex sociopolitical environment of divided nations, we identify several types of (non)visitors to the "other" side, depicted along a continuum (Figure 1). Specifically, two predominant variables influence the visit intentions of Greek Cypriot, "intentionality of the visit" and "actual visitation" as denoted by the visit/non-visit paradox. In turn, intrinsic motives and/or forces 
Figure 1 Continuum of visitation

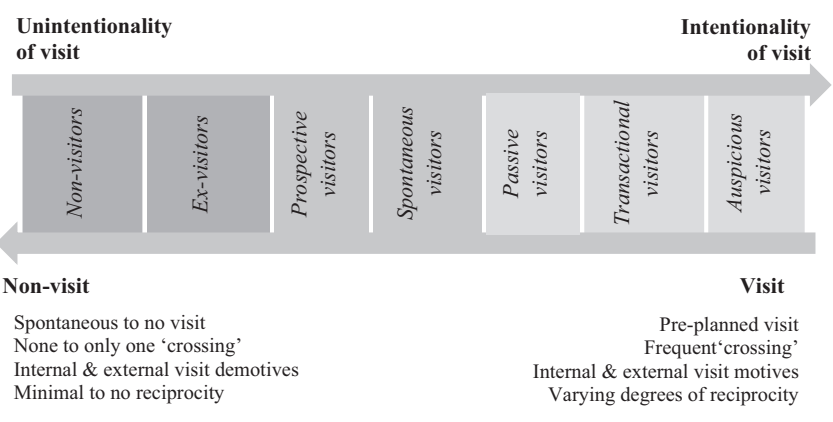

emanating from externalities specific to the context shape intentions to (re)visit. A narrative account by the informants is presented below, taking into consideration the factors motivating and/or demotivating visitation. During the discussion, we exemplify the influence of contextual factors on intentions to (re)visit by drawing on informants' quotations.

\section{Visitors: motives and influencing factors}

Many of the informants cross to the "other" side, albeit for different reasons and at varying frequency. As illustrated in Figure 1, there are several types of visitors. At the one end of the continuum, there is a group of informants - labelled "auspicious visitors" - that appear to have developed personal and social relations with Turkish Cypriots which they wish to strengthen through frequent, mutual visits. These visitors regard it their obligation to cross to the "other" side as frequently as possible to become familiar with the entire Island, both geographically and culturally, even in the absence of ancestral ties. For these informants, the importance of contributing to the reconciliation process influences visitation intentions. The following dialogue between the interviewer (IV) and an informant illustrates these views:

Savvas: For many years, I refused to cross [...] living in Nicosia I by-passed Turkish-Cypriots almost on a daily basis in the supermarket, restaurants, shops [...] then I started talking to Turkish Cypriots online and realised that they were just like us [...] they had the same problems, liked the same music and food and we generally seemed to have more things in common than differences. You don't realise the commonalities unless you interact with them [...].

\section{IV: How often do you visit?}

Savvas: I try to visit at least every two weeks [.. .] there are times when I have to put up a fight to explain to friends and family the importance of getting to know the entire Island of Cyprus and of exercising our right to free movement [...] the younger generation particularly has a role to play in the reunification of our Island [...] if we keep visiting and taking part in bi-communal activities we understand each other better and plant the seed for a prosperous future for all the Cypriots.

In this regard, "auspicious visitors" represent a hopeful force as they acknowledge the importance of their role to reconciliation. Notwithstanding, in Cyprus track one diplomacy activity remains unaffected by the activities of ordinary citizens. In fact, political tensions between the two communities in Cyprus appear to have an adverse effect on track two diplomacy activity. Stephanie, who works for a non-governmental organisation (NGO) promoting reconciliation in Cyprus, argued that "participation in the bi-communal projects has fallen in recent years" following the failure of negotiation talks.

Within the group of "auspicious visitors", we identified Greek Cypriots who were born in the north prior to the division of the Island and who expressed enthusiasm over the ability to visit 
their ancestral homes after the long period of isolation between the two communities. As Anthi stated, "I feel reborn when I visit my village and my friends [...] we grew up together and shared a life and to be able to see them again after so many years is a blessing". For these informants, returning "home" where happy memories existed, is a cathartic process in which nostalgia is a way of negotiating rather than avoiding trauma (Maghbouleh, 2010, as cited in Bonnett, 2015). Legg (2005) suggested that while nostalgia represents problematic engagements with the past, its emphasis on a time and place before the traumatic incident took place, reinforces its description in a non-political narrative. Interestingly, nostalgia emerged as an internal motive encouraging visitation by members of younger generations as well, who were too young to remember their ancestral land or were born after the division of the Island. As Eleni commented "I visited my father's village many times [...] I feel that the village is part of my identity, it does not feel like a foreign land to me because I grew up listening to my father's stories of life in the village". In explaining this "constructed" sense of nostalgia among the younger generation of Greek Cypriots, Zembylas (2014) argued that nostalgic sentiments maybe developed from the memorial narrative of the community that is shaped not only through personal accounts of family members but also through media and education. Unsurprisingly, nostalgic emotions were manifested in the narrative account of young informants with no familial ties to the north, indicating the profound effect the educational policies of the Republic of Cyprus have had on the shaping of young Greek Cypriots' identities (Zembylas, 2014).

Additionally, visitors crossing frequently to the "other" side for external factors including gambling and/or leisure were identified. Due to the nature of their visit, motivated mostly for commercial purposes, we named this sub-group "transactional visitors". For example, Nikos' weekly visits to northern Cyprus are motivated by the lower cost of cigarettes on the "other" side. Likewise, Andreas stated that he visits northern Cyprus frequently to gamble, citing the lack of equivalent gambling establishments in southern Cyprus as the main reason. Despite the current status quo between the two communities, there were informants who visited northern Cyprus for holidays whereas some "transactional visitors" argued to have used the airport in northern Nicosia to fly abroad, highlighting the inexpensive flights and the proximity of the airport as offering a cost-effective and convenient option. Nonetheless, Maria's comment that "many organisations don't cover travel expenses if flying from northern Cyprus" is reminiscent of the negative influence of high politics activity which rests on respective doctrines for political legitimacy and power. Several "transactional visitors" admitted to facing reprimands by some family members and friends over the purpose and/or the commercially based nature of their visit. In this regard, "transactional visitors" seem to remain apathetic towards such criticism, emphasising necessity or similar practices by other Greek Cypriots as pretext. Nonetheless, for some Greek Cypriots crossing to the "other" side represents a negotiated normative practice.

Greek Cypriots' perceived ethical barriers surrounding the act of visitation to the "other" side have been previously recognised as an important influencer (Scott, 2012; Webster and Timothy, 2006). Indeed, this study confirms that for many informants the social pressures of "doing the right thing" emerged as a significant influencer on their decision to visit northern Cyprus. Niki emphasised, "I only cross once in a while to visit the Apostolos Andreas monastery and other religious and cultural attractions". On a similar note, Evangelia commented that she visits northern Cyprus for professional reasons only, as part of her summer tour guiding excursions. Interestingly, throughout the discussion, these informants clarified that when they visit northern Cyprus, they do not engage in commercial or social exchanges with Turkish Cypriots. As Evangelia elaborated, "a Turkish Cypriot tour guide needs to accompany us every time [...] I hardly talk to [them]". Several other informants highlighted that when they do cross, they carry food and drinks with them so that they do not have to spend money in the "pseudo-state", as the Turkish Cypriot administration is referred to by Greek Cypriots. Therefore, we categorised these visitors as "passive visitors" 
due to the unreceptive interaction with Turkish Cypriots. Although the perceived importance of the purpose of the visit appears to justify crossing to the "other" side, the non-reciprocal interaction between "passive visitors" and Turkish Cypriots is unlikely to contribute to reconciliation, unless changes to the status quo take place.

Finally, we identified a group of "spontaneous visitors" which visited northern Cyprus only once despite the lack of intentions to cross to the "other" side. Thus, this study highlights that within the politically uncertain environments, spontaneity in travel is not unlikely. Depicted in the middle of the continuum with a darker shade, this group of visitors claimed that their visit was driven mostly by curiosity and/or prompted by group pressures to cross to the "other" side. The statements of informants in this group are illustrative of the spontaneous nature of their visit, which seems to have been triggered not only due to high politics activity at the time but also because of neutral attitudes towards visiting the "other" side:

Elena: I visited one day with family members who arrived from the UK and expressed a desire to see the occupied areas [...] it was an impulsive decision [ . . ] I never cared about going or not.

Demetra: A friend suggested we cross just to see how it was like [...] at the time and with all these negotiation talks going on I thought why not?

\section{Non-visitors: demotives and influencing factors}

At the other end of the continuum, we identified three groups of non-visitors. Overall, nonvisitation occurred either due to externalities inhibiting a potential visit or negative attitudes towards crossing to the "other" side. For instance, there were informants who are yet to visit the northern part of the Island, despite the absence of negative intentions. Labelled "prospective visitors", and distinguished on the continuum from other non-visitors by a lighter shade, the reasons expressed by this group of informants for not visiting northern Cyprus were not related to negative attitudes. For example, several informants stated that they would like to visit northern Cyprus but given their occupation (e.g. police), a potential visitation would be frowned upon. Likewise, there were informants who expressed a desire to visit but were unable to do so due to transportation limitations or previous speeding tickets that remained unpaid to the ignorance of Greek Cypriots. Communication problems due to language differences were also acknowledged as an inhibiting factor. It is unlikely that high politics activity could positively influence the visit intentions of "prospective visitors" as in this case structural factors appear to shape the ability to cross to the "other" side. Additionally, within this sub-group of prospective visitors, there were those who reluctantly avoided a potential visit as a result of fear of not finding what they expected. In the words of Kyriakos, "I asked my mother if she wanted me to take her to see her village [...] she said no as she prefers to have the memory of her life in the village". As analysis progressed, it became evident that members of the same family or close friends depicted different behaviours with regard to crossing, indicating that visitation to the "other" side was an inherently personal choice.

Moreover, we identified a group of "ex-visitors" representing one-time visitors who had visited northern Cyprus as soon as the crossing restrictions were lifted. For these visitors, visitation was driven mostly by curiosity and the impulsiveness of the excitement over the prospect of being able to cross to the "other" side after many years of isolation. Many of the informants had ancestral ties to northern Cyprus and, therefore, wanted to cross to the "other" side to see their properties. Yet, these informants decided against a future visit due to the difficulty of dealing with the emotional aspects of the visit experience. Bryant (2010) argued that for many Greek Cypriots with ancestral homes in northern Cyprus, the experience of returning as a form of domestic tourist was emotionally difficult. The difficulty of returning to a different reality from what was left behind was also noted by 
Dikomitis (2004). In particular, the visible negligence of villages and towns as well as scared places in northern Cyprus was a regular complaint among many ex-visitors. The statements below illustrate the sentiments dominating the visit experience of ex-visitors whose decision against a revisit constitutes a defensive mechanism, with the importance of maintaining the memories of a beautified "lost homeland" prevailing:

Theodosis: I went once but I will not go again [...] they [Turkish Cypriots] were provocative, with all those Turkish flags and Kemal Ataturk statues [... ] it [the north] changed so much [...] it is not the same as we had left it.

Georgia: When we visited my mum's house, there was a Turkish Cypriot family living there [...] they invited us in but I found the whole experience utterly upsetting. My mum was in her house, only it was not her house anymore [...] we were the guests!

Interestingly, there seems to be a fluidity of roles between visitors and the visited community. For example, while Greek Cypriots with ancestral ties to northern Cyprus had acquired the role of a host when they decided to return with their children and grandchildren, they soon found out that, in fact, they were temporary visitors. In highlighting the social dimension of the host/guest relationship in post-conflict destinations, Causevic and Lynch (2009) argued that the transformation of roles from "old hosts" into "new guests" needs to be seen within the wider social context and as a social catharsis emerging from the rapport between new and old hosts. However, within the complex socio-political environment of Cyprus, whereby political issues remain unresolved, the roles held by each party in the visitor/host relationship is persistently indistinct leading to the reinforcement of negative stereotyping. For instance, several ex-visitors commented on the "bad state" in which they found their properties. Hadjipavlou (2007) warned that in the absence of institutional support for bi-communal contact, old stereotyping of the "former enemy" is reconfirmed. Within this context, there were those who posited that the new inhabitants of their properties lacked concern over the properties as they were not theirs; thereby, distinguishing between Turkish Cypriots, whom they referred to as friendlier and Turks who were depicted as unthoughtful and inattentive of a place that did not belong to them.

While those with ancestral ties to northern Cyprus had returned with reconstructed memories from their visit experience, often rushing to communicate these to others, there were also one-time visitors with no familial link to the "other" side. These visitors had crossed to the "other" side when the checkpoints opened, only to satisfy their curiosity of what is on the "other" side. Once the visit was over, they had no intentions to return regardless of the visit experience. As Chara said, "I've been once to see the place [northern Cyprus] as it seemed they [political leaders] were working on a solution [...] I don't see the point in going back". Perhaps, the dynamic nature in which intention to visit is formed is best depicted by Charis' explanation for his unwillingness to revisit, citing "the provocative political tactics of Turkey and the submissive reaction of Turkish Cypriots to them" as the main reason. Indeed, the political affairs between the two communities appears to negatively influence visit intentions, illustrating that visitation emerges as a (re)negotiated normative practice subjected to external forces. While political tensions were previously identified as an inhibitor on intention to visits (Kim and Prideaux, 2006), high politics activity does not seem to strengthen willingness to revisit northern Cyprus. In fact, ex-visitors' decision not to revisit was greatly influenced by the political tensions that led to the failure of negotiation talks.

The rigidity of negative attitudes between traditional enemies as identified by Anastasopoulos (1992) is best illustrated by the views of "non-visitors". Expressing strong negative sentiments towards a potential visit, this sub-group clarified that unless a political solution between the two communities is found, crossing to the "other" side was not an 
option for them. The rationale for the unwillingness to visit is explained in the statements of the informants below:

Panos: The current status quo is a violation of human rights and international treaties [...] no other country apart from Turkey recognises them [Turkish Cypriot administration] so why should I recognise them by crossing?

\section{Ellie: I refuse to show my passport in my own country!}

Michalis: I wouldn't visit even if you paid me [...] they killed our ancestors, took our villages and towns [...] in my opinion we should not visit to avoid granting them legitimacy and we should not be buying things from them [...] giving them our money.

Konstantinos: I would feel like a traitor if I crossed and to be honest I feel shamed for the Greek Cypriots who visit and spend their money there [...] it doesn't have to do with Turkish Cypriots personally, I am not a racist.

What transpires from these comments is that the current status quo in Cyprus, and in particular the threat of legitimising the Turkish Cypriot administration, has adverse effects on the possibility of a visitation. On the one hand, these informants question the legitimacy of the "border" between the two sides of the Island; on the other hand, their refusal to cross it signifies acknowledgement of its existence (Dikomitis, 2004). This paradox exemplifies the dilemma of crossing which is instilled in many Greek Cypriots since childhood, and arguably, it is difficult to shift. Indeed, Farmaki (2017) posited that the perceptions and attitudes of the opposing group maybe more negative the longer a conflict lasts. After years of isolation, the historic narratives communicated to younger generations about the "other" side, seem to have legitimised the status quo and enhanced collective meaning and behaviour. Although at the outset, it appears that a change in the political affairs between the two communities at the track one diplomacy level is required to elicit visitation, the change in attitudes towards crossing as expressed by "auspicious visitors" reminds us of the dynamic nature of people's perceptions and attitudes. Likewise, context-specific externalities at the macro-level influence interpersonal interactions. A summary of the main reasons motivating and demotivating a potential visit to a hostile outgroup and the underlying influencing factors is presented in Table II.

\section{Table II Summary of factors (de)motivating visitation and influencers}

Factors motivating visitation

Nostalgia

Anticipation for reunification

Initial enthusiasm over ability to cross

Curiosity

Transactional exchanges

Pilgrimage

Professional requirements

Spontaneity

Factors demotivating visitation

Prejudicial attitudes/stereotyping

Fear of unmet expectations

Perceived ethical barriers

Interchangeable visitor/host roles

Personal characteristics (i.e. occupation)

Transportation restrictions

Communication issues
Influencers

Educational policies

Intensity of negotiation talks

Cheaper prices at visited nation

Facilities/attractions at visited nation

Neutral to positive attitudes towards hostile outgroup

Peer pressures

Influencers

Perceived cultural gap

Political tensions

Past visit

Peer pressures/conformity to others' expectations

Status quo between divided nations (e.g. political doctrines of each nation) 


\section{Conclusion and implications}

Overall, the study makes two important contributions. First, it identifies that heterogeneity characterises visitation to a hostile outgroup. As such, it advances existing knowledge by contributing to past studies which merely identified the reasons people would visit (or not) a hostile outgroup. Specifically, the study identified several groups of visitors and non-visitors depicted along a continuum, which reflects the complexity underlying people's travel decision-making when visiting a hostile outgroup (Figure 1). The various types of visitors expressed different reasons for visiting northern Cyprus. For instance, there are visitors who anticipate reconciliation and visit as frequently as possible with the aim of establishing rapport with their counterparts in northern Cyprus. There are Greek Cypriots crossing frequently to the "other" side for commercial reasons only such as buying cigarettes or other goods, which are cheaper in the northern part of the Island. Additionally, visitors cross to the "other" side for pilgrimage and/or professional reasons. Nonetheless, the visit is conditioned by visitors' deliberate passive stance towards the hostile outgroup. For example, several Greek Cypriots were found to avoid exchanges of a personal and/or commercial nature with Turkish Cypriots, with visitation emerging as a negotiated normative practice. In the case of visitors, high politics activity towards reconciliation seems to moderately influence visitation, particularly where the visit occurs spontaneously, encouraged by favourable conditions resulting from track one diplomacy activity. Contrary, the failure and ultimate demise of the negotiation talks between the two communities' political leaders negatively influenced intentions to (re)visit. Specifically, Turkey's interference in the internal politics of Cyprus and economic and political competition between the two communities were acknowledged as potential causes for the failure of the reunification negotiation process. Avoidance of a (re)visit was also attributed to intrinsic factors and, in particular, the emotional burden of returning to ancestral places under a newly acquired role, that of a visitor. Correspondingly, in the case of ex-visitors the ongoing conflict at the macro-level does not contribute to the eradication of negative attitudes acquired post-visitation. Rather, the current status quo seems to further exacerbate the situation.

Consequently, high politics activity appears to play a role in shaping people's intentions to visit a hostile outgroup by establishing the conditions under which intergroup contact may be initiated. Notwithstanding, the rigidity in perceptions and attitudes of people in nations experiencing prolonged political conflict is difficult to shift. In fact, as this study indicated, negative stereotyping may be persistent throughout generations irrespective of gender, age and socio-economic background. However, this study provides some evidence of a possible perceptual and attitudinal change not just following contact with a hostile outgroup but also prior to the visitation. Evidently, the second contribution of this study is that it highlighted the dynamic nature of people's perceptions and attitudes which may change depending on external and internal forces related to the socio-political environment of countries. Even though past studies confirm the adverse effect of political instability on travel behaviour, this study enhances knowledge by highlighting the possibility of change in people's perceptions and attitudes through time, in both favourable and unfavourable terms. In any case, while high politics activity may provide the ground for the cultivation of intergroup contact, it cannot sustain an active, positive form of peace between opposing groups, particularly where there is high-perceived ethnic and cultural diversity deepened by years of conflict and isolation as in the case of Cyprus. Nonetheless, in cases where track one diplomacy failed to yield reconciliation, interpersonal contact brought about by travel may be beneficial if people are receptive towards peacebuilding. Having said that, it must be noted that tourism is only one constituent contributing to reconciliation. The fabric of global society is also influenced by educational policies, media narratives, 
political ideologies and economic circumstances; thus, creating a complex context in which the peace-through-tourism idea remains a challenge.

Conclusively, as the findings of this study are reflective of Greek Cypriots' views only, it remains to be seen how the visitation continuum made explicit in this study may be applied in examinations of Turkish Cypriots' visitation patterns to southern Cyprus. On a practical note, this study reminds us that tourism may benefit the reconciliation process between Cyprus' main communities in numerous ways. For example, tourism may provide the ground for economic cooperation, provided that the status quo offers the appropriate conditions. As this study revealed, economic exchanges between hostile groups exist even in the absence of an institutionalised framework endorsing commercial activities. In addition, tourism as a social activity may be encouraged through the provision of appropriate conditions supporting social interaction. This study illustrated that there are people who are yet to cross to the "other" side despite willingness to do so. Inability to visit can be minimised through the organisation of tours and excursions targeting the youth as well as older generations, which in turn may allow for the establishment of rapport in a safe, controlled environment. For instance, special forms of tourism such as educational or volunteer tourism may signal a departure from mass forms of tourism, which limit interaction between groups. The role of track two diplomacy in the offering of alternative tourism is undoubted. Considering the changes that the global tourism industry is currently undergoing (i.e. sharing economy), the promotion of resource sharing practices may offer a fruitful ground for positive interactions.

Findings from this study are meaningful from two perspectives. First, in light of the current context of increased political and economic instability in which global tourism operates, the study provides significant insights on the influence of socio-political conditions on travel intentions. The global society has recently witnessed the emergence of an array of issues carrying geopolitical implications including the migration crisis and an increase in terrorism. Evidently, as tourism is impacted by such phenomena, insights provided by this study might illuminate understanding of the vulnerability of travel to socio-political conditions and allow for a more informed response by destination managers and tourism planners. Second, the study contributes to the tourism and peace literature by highlighting the complementary role of tourism to reconciliation and opens up new directions of enquiry. Future research may delve deeper into the interplay between tourism and peace by considering the different types of encounters occurring within conflict-affected destinations including service encounters occurring in commercial settings and/or social encounters taking place in non-commercial contexts. Likewise, as the interaction between tourism and politics is dynamic, longitudinal studies are welcomed as are bi-directional investigations comparing the views of opposing groups. Although no differences in the opinions of sub-groups based on demographics were detected in this study, future research of a quantitative nature might delve into the potential differences of views between opposing groups in terms of gender, age category and geographical proximity to the hostile outgroup amongst other variables. Indeed, such information might be particularly valuable to tourism authorities and policymakers. Despite the focus of this study being Cyprus, it is axiomatic that insights are informative to academics, policymakers and practitioners of other destinations experiencing historical conflict. In particular, the study findings have implications for travel between conflictual tourist generating regions and destinations including countries such as Turkey and Greece, Azerbaijan and Armenia, the Korean Peninsula and Palestine and Israel among others, by highlighting the complexity underlying travelrelated decisions in such fragile contexts. We hope that this study serves as a steppingstone for further investigations on the role of tourism to peacebuilding and the influence of political instability on travel-related decisions and behaviours as much is yet to be uncovered in this field of work. 


\section{Note}

1. As the use of geographical terms such as "north" and "south" carry unwonted political connotations in Cyprus, the authors would like to clarify that for the purposes of this paper, our reference to "north" or "northern" and "south" or "southern" implies geographical and not political denotations.

\section{References}

Akis, S., Peristianis, N. and Warner, J. (1996), "Residents' attitudes to tourism development: the case of Cyprus", Tourism Management, Vol. 17 No. 7, pp. 481-494.

Alvarez, M.D. and Campo, S. (2014), "The influence of political conflicts on country image and intention to visit: a study of Israel's image”, Tourism Management, Vol. 40, pp. 70-78.

Anastasopoulos, P.G. (1992), "Tourism and attitude change: Greek tourists visiting Turkey", Annals of Tourism Research, Vol. 19 No. 4, pp. 629-642.

Arana, J.E. and Leon, C.J. (2008), "The impact of terrorism on tourism demand", Annals of Tourism Research, Vol. 35 No. 2, pp. 299-315.

Bonnett, A. (2015), The Geography of Nostalqia: global and Local Perspectives on Modernity and Loss, Routledge, Abingdon.

Bryant, R. (2010), "The state of Cypriot silences”, The Cyprus Review, Vol. 22 No. 2, p. 113.

Causevic, S. and Lynch, P. (2009), "Hospitality as a human phenomenon: host-guest relationships in a post-conflict setting", Tourism and Hospitality Planning \& Development, Vol. 6 No. 2, pp. 121-132.

Causevic, S. and Lynch, P. (2013), "Political (in) stability and its influence on tourism development", Tourism Management, Vol. 34, pp. 145-157.

Chen, C.M. (2010), "Role of tourism in connecting Taiwan and China: assessing tourists' perceptions of the Kinmen-Xiamen links", Tourism Management, Vol. 31 No. 3, pp. 421-424.

Chen, C.C., Lai, Y.H.R., Petrick, J.F. and Lin, Y.H. (2016), "Tourism between divided nations: an examination of stereotyping on destination image", Tourism Management, Vol. 55, pp. 25-36.

Chew, E.Y.T. and Jahari, S.A. (2014), "Destination image as a mediator between perceived risks and revisit intention: a case of post-disaster Japan", Tourism Management, Vol. 40, pp. 382-393.

Cho, M. (2007), "A re-examination of tourism and peace: the case of the Mt. Gumgang tourism development on the Korean peninsula", Tourism Management, Vol. 28 No. 2, pp. 556-569.

Clements, M.A. and Georgiou, A. (1998), "The impact of political instability on a fragile tourism product", Tourism Management, Vol. 19 No. 3, pp. 283-288.

Coshall, J.T. (2003), "The threat of terrorism as an intervention on international travel flows", Journal of Travel Research, Vol. 42 No. 1, pp. 4-12.

D’Amore, L.J. (1988), "Tourism - a vital force for peace", Tourism Management, Vol. 9 No. 2, pp. 151-154.

Diaz-Sauceda, J., Palau-Saumell, R., Forgas-Coll, S. and Sánchez-García, J. (2015), "Cross-border tourists' behavioural intentions: the green line of Nicosia, Cyprus", Tourism Geographies, Vol. 17 No. 5, pp. 758-779.

Dikomitis, L. (2004), "A moving field: Greek Cypriot refugees returning 'home", Durham Anthropology Journal, Vol. 12 No. 1, pp. 7-20.

Drakos, K. and Kutan, A.M. (2003), "Regional effects of terrorism on tourism in three mediterranean countries", Journal of Conflict Resolution, Vol. 47 No. 5, pp. 621-641.

Durko, A. and Petrick, J. (2015), "The Nutella project an education initiative to suggest tourism as a means to peace between the United States and Afghanistan", Journal of Travel Research, Vol. 55 No. 8, pp. 1-13.

Farmaki, A. (2017), "The tourism and peace nexus", Tourism Management, Vol. 59, pp. 528-540.

Farmaki, A., Khalilzadeh, J. and Altinay, L. (2019), "Travel motivation and demotivation within politically unstable nations", Tourism Management Perspectives, Vol. 29, pp. 118-130.

Fisher, R.J. (2001), "Cyprus: the failure of mediation and the escalation of an identity-based conflict to an adversarial impasse", Journal of Peace Research, Vol. 38 No. 3, pp. 307-326. 
Flick, U. (2000), "An introduction to qualitative research", European Journal of Information Systems, Vol. 9 No. 2, pp. 127-127

Guo, Y., Kim, S.S., Timothy, D.J. and Wang, K.C. (2006), "Tourism and reconciliation between mainland China and Taiwan”, Tourism Management, Vol. 27 No. 5, pp. 997-1005.

Hadjipavlou, M. (2007), "Multiple stories: the 'crossings' as part of citizens' reconciliation efforts in Cyprus?", Innovation, Vol. 20 No. 1, pp. 53-73.

Hajibaba, H., Gretzel, U., Leisch, F. and Dolnicar, S. (2015), "Crisis-resistant tourists", Annals of Tourism Research, Vol. 53, pp. 46-60.

Hennink, M., Hutter, I. and Bailey, A. (2010), Qualitative Research Methods, Sage, London.

Higgins-Desbiolles, F. (2003), "Reconciliation tourism: tourism healing divided societies!", Tourism Recreation Research, Vol. 28 No. 3, pp. 35-44.

Holloway, I. and Wheeler, S. (2010), Qualitative Research in Nursing, Blackwell Publishing, Oxford.

Kim, S.S. and Prideaux, B. (2003), "Tourism, peace, politics and ideology: impacts of the Mt. Gumgang tour project in the Korean Peninsula”, Tourism Management, Vol. 24 No. 6, pp. 675-685.

Kim, S.S. and Prideaux, B. (2006), "An investigation of the relationship between South Korean domestic public opinion, tourism development in North korea and a role for tourism in promoting peace on the Korean Peninsula", Tourism Management, Vol. 27 No. 1, pp. 124-137.

Kim, S.S., Prideaux, B. and Prideaux, J. (2007), "Using tourism to promote peace on the Korean Peninsula", Annals of Tourism Research, Vol. 34 No. 2, pp. 291-309.

Legg, S. (2005), "Contesting and surviving memory: space, nation, and nostalgia in les lieux de mémoire", Environment and Planning D: Societv and Space, Vol. 23 No. 4, pp. 481-504.

Litvin, S.W. (1998), "Tourism: the world's peace industry?", Journal of Travel Research, Vol. 37 No. 1, pp. 63-66

McCracken, G. (1988), The Long Interview, Sage, CA, Vol. 13.

Neumayer, E. (2004), "The impact of political violence on tourism: dynamic cross-national estimation", Journal of Conflict Resolution, Vol. 48 No. 2, pp. 259-281.

Podoshen, J.S. and Hunt, J.M. (2011), "Equity restoration, the holocaust and tourism of sacred sites", Tourism Management, Vol. 32 No. 6, pp. 1332-1342.

Pratt, S. and Liu, A. (2016), "Does tourism really lead to peace? a global view", International Journal of Tourism Research, Vol. 18 No. 1, pp. 82-90.

Ritchie, J., Lewis, J., Nicholls, C.M. and Ormston, R. (2014), Qualitative Research Practice, 4th ed., Sage, Los Angeles, CA.

Robinson, O.C. (2014), "Sampling in interview-based qualitative research: a theoretical and practical guide", Qualitative Research in Psychology, Vol. 11 No. 1, pp. 25-41.

Saha, S. and Yap, G. (2014), "The moderation effects of political instability and terrorism on tourism development: a cross-country panel analysis", Journal of Travel Research, Vol. 53 No. 4, pp. 509-521.

Scott, J. (2012), "Tourism, civil society and peace in Cyprus", Annals of Tourism Research, Vol. 39 No. 4, pp. 2114-2132.

Sönmez, S.F. and Graefe, A.R. (1998), "Influence of terrorism risk on foreign tourism decisions", Annals of Tourism Research, Vol. 25 No. 1, pp. 112-144.

Stepchenkova, S., Shichkova, E., Kim, M. and Rykhtik, M.I. (2018), "Do strained bilateral relations affect tourists' desire to visit a country that is a target of animosity?", Journal of Travel \& Tourism Marketing, Vol. 35 No. 5, pp. 553-566.

Tomljenovic, R. (2010), "Tourism and intercultural understanding or contact hypothesis revisited", Tourism. Progress and Peace, pp. 17-34.

Webster, C. and Timothy, D.J. (2006), "Travelling to the 'other side': the occupied zone and greek cypriot views of crossing the green line", Tourism Geographies, Vol. 8 No. 2, pp. 162-181.

Zembylas, M. (2014), "Nostalgia, postmemories, and the lost homeland: exploring different modalities of nostalgia in teacher narratives", Review of Education, Pedagogy, and Cultural Studies, Vol. 36 No. 1, pp. 7-21. 


\section{Further reading}

Clifton, K.J. and Handy, S.L. (2003), "Qualitative methods in travel behaviour research", in Transport Survev Quality and Innovation, Emerald Group Publishing Limited, Bingley, pp. 283-302.

Farmaki, A. and Antoniou, K. (2017), "Politicising dark tourism sites: evidence from Cyprus", Worldwide Hospitality and Tourism Themes, Vol. 9 No. 2, pp. 175-186.

Sonmez, S.F. and Apostolopoulos, Y. (2000), "Conflict resolution through tourism cooperation? the case of the partitioned island-state of Cyprus", Journal of Travel \& Tourism Marketing, Vol. 9 No. 3 , pp. 35-48.

\section{About the authors}

Anna Farmaki is Lecturer in Tourism Management at the School of Management and Economics at the Cyprus University of Technology. Her research interests lie in the areas of tourism planning and development and tourist behaviour. Anna Farmaki is the corresponding author and can be contacted at: anna.farmaki@cut.ac.cy

Katerina Antoniou is Lecturer at the School of Business and Management, University of Central Lancashire Cyprus. Her research interests revolve around post-conflict development, peace and conflict and international relations.

Prokopis Christou is Lecturer at the School of Management and Economics at the Cyprus University of Technology. His research interests are concerned with tourism sustainability and the tourist psychological and spiritual experience.

For instructions on how to order reprints of this article, please visit our website: www.emeraldgrouppublishing.com/licensing/reprints.htm

Or contact us for further details: permissions@emeraldinsight.com 